\title{
Alzheimer hastalığında demans düzeyinin vücut kompozisyonuna ve bazal metabolizma hızına etkisi
}

\author{
The effect of dementia level on body composition and basal metabolic rate in Alzheimer's \\ disease
}

Hülya Özkan, Ayten Üstündağ

Gönderilme tarihi: 09.06.2020

Kabul tarihi: 02.12.2020

\section{Özet}

Amaç: Alzheimer hastalığı $(\mathrm{AH})$, bilişsel fonksiyonların geri dönüşümsüz kaybı ile karakterize ilerleyici nörodejeneratif ve multifaktoriyel etyolojiye sahip bir hastalıktır. Bu hastalarda gelişen beslenme bozuklukları kognitif yıkımın artmasına, dolayısıyla demansın ilerlemesine neden olabilmektedir. Biz bu çalışmada, $\mathrm{AH}$ hastalarında hastalığın evrelerine göre kilo, vücut kütle indeksi (VKI), yağsız vücut kütlesi ile bazal metabolizma hızı $(\mathrm{BMH})$ arasındaki ilişkiyi araştırmak ve $\mathrm{BMH}$ üzerine etkili olabilecek klinik ve laboratuvar bulgularını incelemeyi amaçladık.

Gereç ve yöntem: 108 (44 erkek, 64 kadın) AH hastasının klinik ve demografik özellikleri kayıt edildi. Hastalar Klinik Demans Evrelendirme Ölçeğine göre hafif ve hafif-orta evre AH (Grup 1, n=84) ile orta ve ağır evre $\mathrm{AH}$ (Grup 2, n=24) olmak üzere iki gruba ayrıldı. Hastaların kilo, boy, bel çevresi ölçümleri ve laboratuvar tetkikleri kayıt edildi. Hastaların VKi Quetelet indeksine, yağsız vücut kütlesi Hume denklemi ve BMH düzeyleri de HarrisBenedict denklemine göre hesaplandı.

Bulgular: Hastaların ortalama yaşı $71,6 \pm 8,2$ yıl, ortalama VKI $30,6 \pm 39,8 \mathrm{~kg} / \mathrm{m}^{2}$ ve ortalama demans süresi 33,8 $\pm 29,4$ ay olarak saptandı. Grup 1 ve Grup 2 arasında cinsiyet, yaş, VKi, bel çevresi, demans süreleri açısından fark tespit edilmedi, buna karşın orta ve ağır evre AH hastalarında, hafif evre grubuna göre yağsız vücut kütlesi ve $\mathrm{BMH}$ düzeylerinin daha düşük olduğu saptandı $(p<0,05)$. AH hastalarında VKİ düzeyinin, bel çevresinin ve yağsız vücut kütlesinin BMH ile pozitif ilişkili olduğunu saptadık. Yağsız vücut kütlesinin BMH'nı etkileyen bağımsız faktör olduğu tespit edildi $(\beta=0,732, p<0,001, \mathrm{OR}=11,06, \mathrm{Cl} \% 95$ 11,07-15,9).

Sonuç: İleri evre AH hastalarında kilo kaybının özellikle yağsız vücut kütlesindeki azalmanın hastaların yaşam kalitesini olumsuz etkileyebileceğini, hastalığın başlangıç döneminden itibaren doğru beslenme ve egzersiz programlarının uygulanmasının önemli olduğunu düşünmekteyiz.

Anahtar kelimeler: Alzheimer hastalığı, demans, bazal metabolizma hızı.

Özkan H, Üstündağ A. Alzheimer hastalığında demans düzeyinin vücut kompozisyonuna ve bazal metabolizma hızına etkisi. Pam Tıp Derg 2021;14:201-207.

\begin{abstract}
Purpose: Alzheimer's disease (AD) is a progressive neurodegenerative disease characterized by irreversible loss of cognitive functions and has multifactorial etiology. Nutritional disorders in Alzheimer's disease (AD) patients may lead to an increase in cognitive impairment and subsequent progression of dementia. In this study, we aimed to investigate the relationship of basal metabolic rate (BMR) with weight, body mass index (BMI), lean body mass in AD patients and to clarify the clinical and laboratory findings that may affect BMR.

Materials and methods: The clinical and demographic characteristics of 108 patients (44 men, 64 women) were recorded. The patients were divided into two groups according to Clinical Dementia Rating Scale as mild and mild-moderate AD (Group 1, $n=84$ ) and moderate and severe AD (Group 2, $n=24$ ). The patients' weight, height, waist circumference measurements and laboratory tests were recorded. The patients' BMI Quetelet indestia, lean body mass Hume equation and BMH levels were also calculated according to Harris-Henedict equation.

Results: The mean age of the patients was $71.6 \pm 8.2$ years, the mean BMI was $30.6 \pm 39.8 \mathrm{~kg} / \mathrm{m}^{2}$ and the mean dementia duration was $33.8 \pm 29.4$ months. No difference was found between Group 1 and Group 2 in terms of gender, age, BMI, waist circumference, dementia duration, whereas lean body mass and BMR levels were found to be lower in moderate and severe AD patients compared to mild stage group $(p<0,05)$. BMI, waist circumference and lean body mass were positively correlated with BMR in AD patients. Lean body mass was found to be an independent factor affecting BMR $(\beta=0.732, p<0,001, \mathrm{OR}=11.06, \mathrm{Cl} 95 \% 11.07-15.9)$.

Conclusion: We found a significant weight loss, especially in lean body mass, that may adversely affect the quality of life in advanced AD patients. It is important to implement proper nutrition and exercise programs from the onset of the disease.
\end{abstract}

Key words: Alzheimer's disease, dementia, basal metabolic rate.

Hülya Özkan, Dr. Öğr. Üye. Trakya Üniversitesi Tıp Fakültesi, Nöroloji Anabilim Dalı, Edirne, Türkiye, e-posta: dr hulyaozkan@yahoo.com (orcid.org/0000-0002-3427-0354) (Sorumlu Yazar)

Ayten Üstündağ, Dr. Öğr. Üye. Trakya Üniversitesi Tıp Fakültesi, İç Hastalıkları Anabilim Dalı, Genel Dahiliye Bilim Dalı, Edirne, Türkiye, e-posta: ustundagayten@yahoo.com.tr (orcid.org/0000-0003-1077-2795) 
Ozkan H, Ustundag A. The effect of dementia level on body composition and basal metabolic rate in Alzheimer's disease. Pam Med J 2021;14:201-207.

\section{Giriş}

Demans, bilişsel fonksiyonların geri dönüşümsüz kaybı ile karakterize ilerleyici bir nörodejeneratif hastalıktır [1]. Demansın en sık nedeni Alzheimer hastalığıdır (AH). Çalışmalarda uygulanan metoda bağlı olarak toplumda görülme sıklığı \%3,6-23 arasında değişmektedir. Yaşın ilerlemesi ile hastalığın görülme sıklığı artmakta, 85 yaş üstündeki prevalansı \%50'ye ulaşmaktadır [2].

Günümüzde AH'nın etiyolojisi halen tam aydınlatılamamıştır. Yaş, kadın cinsiyet, aile hikayesinin varlığı $\mathrm{AH}$ gelişiminde önemli risk faktörleridir [3, 4]. Ayrıca toplumda sık görülen hipertansiyon, diyabet, hiperlipidemi, inme gibi hastalıkların yanı sıra alüminyum, kurşun, bakır gibi toksik maddelere maruz kalma, vitamin B12 eksikliği, östrojen eksikliği, düşük sosyoekonomik durum, sigara kullanımı gibi birbirinden farklı birçok risk faktörünün $\mathrm{AH}$ gelişiminde rol oynayabileceği ileri sürülmektedir $[5,6]$.

Alzheimer hastalığının erken evresinde kelime bulmada zorlanma, yeni bilgi öğrenme ve entelektüel kapasitelerde azalma söz konusu iken, orta evrede hafıza kaybında artış, uykusuzluk hali, akraba ve yakınlarını tanıyamama, iletişimde zorlanma, halüsinasyonlar, ileri evrede ise öz bakım sorunları, yatağa bağımlıı ve konuşamama gibi sorunlar ön plana çıkmaktadır. Birçok Alzheimer hastasının ölüm nedeni enfeksiyonlar, bası yaraları, emboli ve beslenme sorunlarının neden olduğu hastalıklardır [7].

Alzheimer hastalarında kilo kaybı sık karşılaşılan bir tablodur. Ulusal Nörolojik ve İletişim Bozuklukları ve İnme EnstitüsüAlzheimer Hastalığı ve Illişkili Hastalıklar Derneği (NINCDS-ADRDA) kilo kaybının AH tanısı ile uyumlu klinik bulgulardan birisi olduğunu bildirmektedir [8]. Kronik ve ciddi hastalıkların seyri sırasında görülen kilo kaybı genel olarak, bası yaralarının ve sistemik enfeksiyonların gelişimine zemin hazırlarken, kilo kaybına eşlik eden kas kütlesindeki azalmalar da bakım sürecinin ağırlaşmasına yol açar. Diğer yandan Alzheimer hastalarında gelişen beslenme bozuklukları kognitif yıkımın artmasına, dolayısıyla demansın ilerlemesine de neden olabilmektedir [9]. Bu çalışmada, $\mathrm{AH}$ tanısı alan hastalarda hastalığın evrelerine göre kilo, vücut kütle indeksi, yağsız vücut kütlesi ile bazal metabolizma hızı (BMH) arasındaki ilişkinin araştırılması ve BMH üzerine etkili olabilecek klinik, laboratuvar bulgularının incelenmesi amaçlanmıştır.

\section{Gereç ve yöntem}

Trakya Üniversitesi Tıp Fakültesi Nöroloji Polikliniği'ne ardışık olarak başvuran ve yapılan değerlendirmeler neticesinde Alzheimer Hastalığı tanısı alan 108 hasta (44 erkek, 64 kadın) çalışmaya dahil edildi. Çalışma için Trakya Üniversitesi Tıp Fakültesi Bilimsel Araştırmalar Etik Kurulu'ndan onay alındı. AH'nın tanısı DSM-IV ve NINCDS-ADRDA kriterlerine [8, 10] göre konuldu. Hastaların özgeçmiş bilgileri (Diabetes Mellitus, hipertansiyon, inme, koroner kalp hastalığı, kullanılan ilaçlar, sigara-alkol kullanımı) sorgulandı. Kronik alkolizm, beyin tümörü, klinik depresyon, malignite, aşikar hiper/ hipotiroidi, son dönem böbrek yetersizliği, ilaç kullanımı (kortikosteroid, östrojen) dışlama kriterleri olarak belirlendi. Hastaların demans düzeyleri ve işlevsel bozuklukları "Klinik Demans Evrelendirme Ölçeği (CDR)" ile değerlendirildi $[11,12]$. Demans evrelendirme sonuçlarına göre 84 hastada hafif ve hafif-orta düzeyde demans, 19 hastada orta düzeyde demans ve 5 hastada ağır demans saptandı. Orta ve ağır demans gruplarında hasta sayısı az olduğundan bu olgular aynı grupta birleştirildi. Hafif ve hafiforta düzeyde demansı saptanan hastalar Grup $1(n=84)$ ile orta ve ağır demansı olan hastalar Grup 2 ( $n=24)$ olarak tanımlandı. Tüm hastaların kilo, boy, bel çevresi ölçümleri standartlara uygun şekilde yapıldı. Hastaların laboratuvar tetkikleri (açlık kan glukozu, açlık insülin, TSH ve lipid düzeyleri) kayıt edildi. Tüm hastaların vücut kütle indeksi Quetelet indeksine [13], yağsız vücut kütlesi Hume denklemine [14] ve $\mathrm{BMH}$ düzeyleri de Harris-Benedict denklemine [15] göre hesaplandı (Tablo 1).

\section{İstatistiksel analizler}

Verilerin analizleri için SPSS 18.0 programı kullanıldı. Verilerin Kolmogorov-Smirnov testi yapılarak parametrik dağılım ve non- 
Tablo 1. Vücut kütle indeksi, vücut yağ kütlesi ve bazal metabolizma hızı denklemeleri

\begin{tabular}{ll}
\hline $\begin{array}{l}\text { Vücut Kütle İndeksi } \\
\text { (Quetelet indeksi) }\end{array}$ & $\begin{array}{l}\text { Kilo / Boy }{ }^{2} \\
\text { (kilo; kg, boy; } m)\end{array}$ \\
$\begin{array}{l}\text { Yağsız Vücut Kütlesi } \\
\text { (Hume denklemi) }\end{array}$ & $\begin{array}{l}\text { Erkek için; }(0,32810 \times \text { kilo })+(0,33929 \times \text { boy })-29,5336 \\
\text { Kadın için; }(0,29569 \times \text { kilo })+(0,41813 \times \text { boy })-43,2933 \\
\text { (kilo; kg, boy; } \mathrm{cm})\end{array}$ \\
$\begin{array}{l}\text { Bazal Metabolizma Hızı } \\
\text { (Harris-Benedict Denklemi) }\end{array}$ & $\begin{array}{l}\text { Erkek için; } 66,5+(13,75 \times \text { kilo })+(5,003 \times \text { boy })-(6,775 \times \text { yaş }) \\
\text { Kadın çin; } 655,1+(9,563 \times \text { kilo })+(1,85 \times \text { boy })-(4,676 \times \text { yaş })\end{array}$ \\
\hline
\end{tabular}

parametrik dağılımları incelendi. Klinik ve laboratuvar verilerinin kıyaslanmasında kikare, Student-t testi ve Mann-Withney-U testi kullanıldı. Verilerin ilişkileri Pearson korelasyon ve Spearman korelasyon analizleriyle saptandı. BMH'yı etkileyen faktörlerin saptanması için Stepwise Lojistik Regresyon testi uygulandı. $P<0,05$ istatistiksel olarak anlamlı kabul edildi.

\section{Bulgular}

Çalışmaya dahil edilen toplam 108 Alzheimer hastasının (\%59,2 kadın, \%40,7 erkek) ortalama

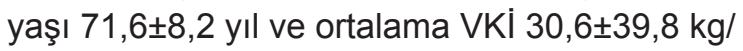
$\mathrm{m}^{2}$ idi. Çalışmaya katılan hastaların ortalama demans süresi $33,8 \pm 29,4$ ay olarak saptandı.
Klinik Demans Evrelendirme Ölçeğine göre hastalar, hafif demans grubu (Grup 1) ve ortaağır demans grubu (Grup 2) olarak ayrıldı. Grup 1 ve Grup 2 arasında cinsiyet, yaş, VKI, bel çevresi, demans süreleri açısından fark tespit edilmedi. Buna karşın, orta-ağır demans düzeyi olan Alzheimer hastalarında, hafif demans grubuna göre yağsız vücut kütlesi $(p<0,05)$ ve $\mathrm{BMH}(p<0,05)$ düzeylerinin daha düşük olduğu saptandı. Hipertansiyon oranı Grup 1'de Grup 2'ye göre daha yüksekti $(p<0,05)$. Laboratuvar parametreleri açısından, iki grup arasında istatistiksel olarak anlamlı fark saptanmadı. Grupların klinik ve laboratuvar verileri Tablo 2'de gösterilmiştir.

Tablo 2. Alzheimer hastalarının demans düzeylerine göre klinik ve laboratuvar verileri

\begin{tabular}{|c|c|c|c|}
\hline & $\begin{array}{l}\text { Grup } 1(n=84) \\
\text { hafif ve hafif-orta evre } \\
\text { Alzheimer Hastalığı } \\
\text { olanlar }\end{array}$ & $\begin{array}{l}\text { Grup } 2(n=24) \\
\text { orta ve ağır evre } \\
\text { Alzheimer Hastalığı olanlar }\end{array}$ & $p$ \\
\hline Kadın/Erkek & $48 / 36$ & $16 / 8$ & * \\
\hline Yaş (yıl) & $71,8 \pm 7,6$ & $67,8 \pm 9,3$ & * \\
\hline VKI $\left(\mathrm{kg} / \mathrm{m}^{2}\right)$ & $32,3 \pm 45,1$ & $24,8 \pm 4,2$ & $<0,05$ \\
\hline Bel çevresi (cm) & $94,2 \pm 16,3$ & $88,4 \pm 18,1$ & * \\
\hline Yağsız vücut kütlesi (kg) & $46,3 \pm 7,3$ & $39,5 \pm 12,9$ & $<0,05$ \\
\hline BMH (kcal/gün) & $1345,9 \pm 178,5$ & $1260,8 \pm 121,7$ & $<0,05$ \\
\hline Demans süresi (ay) & $32,4 \pm 30,2$ & $38,5 \pm 26,7$ & * \\
\hline Açlık kan glukozu (mg/dl) & $110,1 \pm 29,3$ & $106,2 \pm 29,8$ & * \\
\hline Açlık insülini (ulU/ml) & $12,3 \pm 16,8$ & $14,6 \pm 11,9$ & * \\
\hline Kolesterol (mg/dl) & $206,6 \pm 46,9$ & $201,3 \pm 30,9$ & * \\
\hline Trigliserid (mg/dl) & $137,3 \pm 75,9$ & $128,2 \pm 92,6$ & * \\
\hline HDL-k (mg/dl) & $52,0 \pm 32,9$ & $53,1 \pm 18,4$ & * \\
\hline LDL-k (mg/dl) & $131,6 \pm 32,9$ & $124,7 \pm 29,5$ & * \\
\hline TSH (IU/I) & $3,04 \pm 10,7$ & $1,2 \pm 0,5$ & * \\
\hline DM varlığı (\%) & $\% 32$ & $\% 17$ & * \\
\hline Hipertansiyon varlığı(\%) & $\% 68$ & $\% 41$ & $<0,05$ \\
\hline Aile öyküsü varlığı (\%) & $\% 39$ & $\% 37$ & * \\
\hline Sigara kullanımı (\%) & $\% 14$ & $\% 16$ & * \\
\hline
\end{tabular}

${ }^{*} p>0,05$

VKİ: Vücut Kütle İndeksi, BMH: Bazal Metabolizma Hızı, HDL-k: High Density Lipoprotein-kolesterol

LDL-k: Low Density Lipoprotein-kolesterol, TSH: Tiroid Stimule edici Hormon, DM: Diabetes Mellitus 
Alzheimer hastalarında BMH ile ilişkili klinik ve laboratuvar verileri incelendiğinde VKİ düzeyinin, bel çevresinin ve yağsız vücut kütlesinin $\mathrm{BMH}$ ile pozitif ilişkili olduğunu saptadık (Tablo 3). Yaş, cinsiyet, demans süresi, diyabet ve hipertansiyon varlığı ile $\mathrm{BMH}$ arasında ilişki saptanmadı. Stepwise lojistik regresyon analizinde ise yağsız vücut kütlesinin, diğer özelliklerden bağımsız olarak, BMH'yı etkileyen faktör olduğu tespit edildi $(\beta=0,732$, $p<0,001, \mathrm{OR}=11,06, \mathrm{Cl} \% 95$ 11,07-15,9).

Tablo 3. Alzheimer hastalarında Bazal Metabolizma Hızının Vücut Kütle İndeksi düzeyi, bel çevresi ve yağ kütlesi ile arasındaki ilişki

\begin{tabular}{llll}
\hline & Vücut Kütle İndeksi & Bel çevresi & Yağsız Vücut Kütlesi \\
Bazal Metabolizma Hızı & $\boldsymbol{p}<0,01$ & $\boldsymbol{p}<0,001$ & $\boldsymbol{p}<0,001$ \\
& $\mathrm{r}=0,481$ & $\mathrm{r}=0,635$ & $\mathrm{r}=0,732$ \\
\hline
\end{tabular}

\section{Tartışma}

$\mathrm{Bu}$ çalışmada, kilo kaybının ağır evre Alzheimer hastalarında hafif demansı olanlara göre daha fazla olduğunu ve yağsız vücut kütlesindeki azalmanın sonucunda da bazal metabolizma hızının düştüğünü saptadık.

Yapılan çalışmalarda, Alzheimer hastalarında kilo kaybının sık karşılaşılan klinik bulgulardan biri olduğu bildirilmektedir. Alzheimer hastalarının değerlendirildiği bir çalışmada, $\mathrm{AH}$ olmayanlara göre \%5'in üzerinde kilo kaybının 2 kat fazla olduğu tespit edilmiştir [16]. Wolf Klein ve ark. [17] da, bir yıllık takip sonucunda kilo kaybının Alzheimer hastalarında kontrol grubuna göre (\%92'ye karşılık \%39) daha fazla olduğunu saptamışlardır. Araştırmacılar hastalarda bozulmuş vücut kilo dengesi olduğunu ileri sürmüşlerdir. Kabul edilen en genel görüş AH'nın ilerleyişine paralel olarak kilo kaybının geliştiği, özellikle ileri evrede kilo kaybının daha da fazla olduğu şeklindedir. Berlinger ve Potter [18], ileri yaşta demansı olanlarda olmayanlara göre VKI'nin \%10 daha düşük olduğunu bildirmişlerdir. Biz de çalışmamızda, Alzheimer hastalarında VKI düzeylerinin ortaağır evre demansı olanlarda, hafif demansı olanlara göre daha düşük olduğunu tespit ettik. Yapılan çalışmalarda, Alzheimer hastalarındaki kilo kaybının azalmış enerji alımı ve/veya artmış enerji tüketimi ile ilişkili olup olmadığı ya da santral sinir sistemindeki değişimlere bağlı olup olmadığı hakkında fikir birliği bulunmamaktadır. Grundman ve ark. [19], Alzheimer hastalarının yeme alışkanlıklarının kontrol edildiği mezial temporal kortekste oluşan atrofinin sonucunda kilo verdiklerini ileri sürmüşlerdir. Diğer çalışmalarda ise, hastalığın ilerlemesi ile bakım sorunlarının artması, gıdaya ulaşmadaki zorluklar, beslenme tercihlerindeki değişimler ve gıda volümündeki azalmalar sonucunda kilo kaybının olduğu ileri sürülmektedir. Yaşlılarda kilo kaybına eşlik eden çeşitli vitamin ve yağ asidi eksiklikleri, oksidatif stresin ve doku hasarının artmasına yol açarak kognitif yıkıma neden olabilir [20, 21]. Diğer yandan demans geliştikten sonra hipotalamustaki açlık-tokluk merkezindeki değişimler ve beslenme hataları da mevcut kilo kaybının daha da ağırlaşmasına neden olabilir [22]. Bizim çalışmamızda da, ileri evre demansı olanlarda VKl'nin düşük olması bu evredeki hastaların beslenme sorunlarının ön planda olabileceğini düşündürmektedir.

Günlük enerji ihtiyacı, istirahat halinde bazal metabolizmanın sürdürülmesiiçingerekenenerji, fizik aktiviteyle harcanacak enerji ve gıdaların neden olduğu termik enerjinin toplamıdır. Toplam enerji ihtiyacının büyük kısmını (\%60$80)$, vücut fonksiyonlarının ve homeostazının normal olarak devam edebilmesi için gereken bazal enerji tüketimi oluşturur [23]. Kişinin kilosu, vücut kompozisyonu, yaş, cinsiyet, gebelik, altta yatan hastalıklar, hormonların işleyişi, uyku durumu, ateşli hastalıklar, bazı ilaçlar doğrudan günlük enerji ihtiyacını değiştirmektedir [24]. Günümüzde günlük enerji tüketiminin tüm parametrelerini aynı anda değerlendiren güvenilir metodlar bulunmamaktadır. Ancak çalışmalarda enerji tüketiminin hesaplanması için, invaziv yöntemlerin yanı sıra indirekt kalorimetre, solunum gazlarının değişimi analizi gibi invaziv olmayan yöntemler kullanılmaktadır [25]. İstirahat ve postprandiyal enerji tüketimini değerlendiren indirekt kalorimetre yöntemi günlük enerji tüketiminin saptanmasında altın standart olarak kabul edilmektedir [26]. Ancak bu yöntemin teknik desteğe intiyaç göstermesi ve maliyetinin yüksek olmasından 
dolayı kullanım alanı kısıtlıdır. $\mathrm{Bu}$ nedenle BMH'nın saptamasında indirekt kalorimetre ile uyum gösteren yaş, cinsiyet, kilo ve boy gibi özelliklerin kullanıldığı çeşitli denklemler tespit edilmiştir. Kronik hastalıkların enerji dengesi üzerine etkilerini araştıran çalışmaların çoğunda $\mathrm{BMH}$ denklemleri kullanılmaktadır [27]. BMH tahmin denklemleri konusunda daha fazla araştırmaya intiyaç duyulduğu vurgulanan ve Latin Amerika'da geriatrik popülasyonda gerçekleştirilen bir çalışmada ölçülen BMH'yı en iyi yansıtan denklemlerin Harris-Benedict ve Lührmann olduğu bildirilmiştir [28].

Yaşılarla yapılan çalışmalarda, kronik
hastalıkların bazal metabolizma hızın
etkileyerek enerji dengesini değiştirdikleri saptanmıştır. Yaşlılıkta kronik hastalıkların seyri sırasında BMH'nın arttığı, buna bağlı olarak kilo kaybının geliştiği ileri sürülmektedir [29]. Diğer yandan kronik hastalığı olan yaşılıarda çift işaretli su metodu ile yapılan enerji metabolizmasına yönelik çalışmalar, konu hakkında daha net bilgilerin açığa çıkmasına neden olmuştur. Günümüze kadar gerçekleştirilen ve Alzheimer hastalarında bazal metabolik hızı değerlendiren çalışmaların sonuçları çelişkilidir. Doorduijn ve ark. [30], bilişsel olarak normal kontrollerle karşılaştırıldığında, Alzheimer hastalarında bazal metabolik hızın daha yüksek olduğunu bildirmişlerdir. Niskanen ve ark.'da [31], BMH'nın Alzheimer hastalarında kontrol grubu ile benzer olduğunu saptamışlardır. Poehlman ve Dvorak [32], kontrol grubuna göre Alzheimer hastalarında günlük enerji tüketiminin ve BMH'nın daha düşük olduğu, özellikle kaşektik olan alt grupta BMH'nın daha da azaldığını bildirmişlerdir. Bu çalışma sonucunda, Alzheimer hastalarında BMH'daki değişimin kilo kaybından sorumlu olamayacağı ileri sürülmüştür. Biz de çalışmamızda, ağır evre Alzheimer hastalarında BMH'yı hafif evre demansı olanlara göre daha düşük saptadık. Ayrıca demansı ilerlemiş hastalarda azalmış VKİ düzeyi yanı sıra yağsız vücut kütlesinin de azalmış olduğunu tespit ettik. Orta dereceli kognitif yıkımı olanlarda \%4 kilo kaybının demans gelişimini 3,4 kat, $\mathrm{AH}$ gelişimini 3,2 kat arttırdığı gösterilmiştir [33]. Özellikle yağsız vücut kütlesindeki azalmanın Alzheimer hastalığının ilerlemesine neden olduğu, bu durumun da beyindeki atrofi ve kognitif performansla ilişkili olduğu gösterilmiştir [34]. Santos ve ark.'nın [35] çalışmasında da, yaşlı Alzheimer hastalarında beslenme sorunlarının kilo ve yağsız vücut kütlesinde kayba yol açtığı, özellikle ileri evre hastalarda kognitif fonksiyonlardaki azalma ile vücut kompozisyonundaki değişimler arasında ilişki olduğu gösterilmiştir. Bizim çalışmamızda da, hastalığın ilerlemesi ile vücut kompozisyonu arasında ilişki saptanmıştır. Özellikle yağsız vücut kütlesi içinde yer alan periferik kas kütlesindeki azalmalar yaşlılarda hareket sorunlarına yol açarken, mortaliteye katkıda bulunmaktadır. Diğer yandan enerji dengesi üzerine yapılan incelemelerde, yağsız vücut kütlesinin BMH'nın en önemli belirleyicisi olduğu bildirilmektedir [36]. Biz de çalışmamızda, Alzheimer hastalarında BMH üzerine yağsız vücut kütlesinin ana belirleyici faktör olduğunu tespit ettik.

Çalışmamızın sonucunda, ağır evre Alzheimer hastalarında kilo kaybının özellikle yağsız vücut kütlesindeki azalmanın hastaların yaşam kalitesini olumsuz etkileyebileceğini, hastalığın başlangıç döneminden itibaren doğru beslenme ve egzersiz programlarının uygulanmasının önemli olduğunu düşünmekteyiz. Ancak bu bulguların hastalığın doğal sonucu olarak ortaya çıkıp çıkmadığı, beslenme bozukluğunun hastalığının ilerlemesine katkı sağlayıp sağlamadığını aydınlatmak için yeni çalışmalara intiyaç vardır.

Çıkar ilişkisi: Yazarlar çıkar ilişkisi olmadığını beyan eder.

\section{Kaynaklar}

1. Knopman DS, Boeve BF, Petersen RC. Essentials of the proper diagnoses of mild cognitive impairment, dementia, and major subtypes of dementia. Mayo Clin Proc 2003;78:1290-1308. https://doi. org/10.4065/78.10.1290

2. Prince M, Bryce R, Albanese E, Wimo A, Ribeiro $W$, Ferri CP. The global prevalence of dementia: a systematic review and metaanalysis. Alzheimers Dement 2013;9:63-75 https://doi.org/10.1016/j. jalz.2012.11.007

3. Gao S, Hendrie HC, Hall KS, Hui S. The relationships between age, sex, and the incidence of dementia and Alzheimer disease. Arch Gen Psychiatry 1998;55:809815. https://doi.org/10.1001/archpsyc.55.9.809

4. Williamson J, Goldman J, Marder KS. Genetic aspects of Alzheimer disease. Neurologist 2009;15:80-86. https://doi.org/10.1097/NRL.0b013e318187e76b 
5. Cardoso BR, Cominetti C, Cozzolino SMF. Importance and management of micronutrient deficiencies in patients with Alzheimer's disease. Clin Interv Aging 2013;8:531-542. https://doi.org/10.2147/CIA.S27983

6. Aliev G, Ashraf GM, Kaminsky YG, et al. Implication of the nutritional and nonnutritional factors in the context of preservation of cognitive performance in patients with dementia/depression and alzheimer disease. Am J Alzheimers Dis Other Demen 2013;28:660-670. https:// doi.org/10.1177/1533317513504614

7. Lopez OL, Dekosky ST. Clinical symptoms in Alzheimer's disease. Handb Clin Neurol 2008;89:207216. https://doi.org/10.1016/S0072-9752(07)01219-5

8. McKhann G, Drachman D, Folstein M, Katzman R, Price D, Stadlan EM. Clinical diagnosis of Alzheimer's disease: report of the NINCDS-ADRDA Work Group under the auspices of department of health and human services task force on Alzheimer's disease. Neurology 1984;34:939-944. https://doi.org/10.1212/wnl.34.7.939

9. Burns A, Marsh A, Bender DA. Dietary intake and clinical, anthropometric and biochemical indices of malnutrition in elderly demented patients and nondemented subjects. Psychol Med 1989;19:383-391. https://doi.org/10.1017/s0033291700012423

10. American Psychiatric Association. Diagnostic and Statistical Manual of Mental Disorders, Fourth Edition (DSM-IV). Washington, 1994;143-147.

11. Morris J. The clinical dementia rating (CDR): current version and scoring rules. Neurology 1993;43:24122414. https://doi.org/10.1212/wnl.43.11.2412-a

12. Gürvit IH, Baran B. Scales in dementia and cognitive disorders. Arch Neuropsychiatry 2007;44:58-65.

13. Gadzik J. "How much should I weigh?" Quetelet's equation, upper weight limits, and BMI prime. Conn Med 2006;70:81-88.

14. Hume R. Prediction of lean body mass from height and weight. J Clin Path 1966;19:389-391. https://doi. org/10.1136/jcp.19.4.389

15. Harris JA, Benedict FG. A biometric study of human basal metabolism. Proc Natl Acad Sci USA 1918;4:370373. https://doi.org/10.1073/pnas.4.12.370

16. White $\mathrm{H}$, Pieper $\mathrm{C}$, Schmader $\mathrm{K}$, Fillenbaum G. Weight change in Alzheimer's disease. J Am Geriatr Soc 1996;44:265-272. https://doi. org/10.1111/j.1532-5415.1996.tb00912.x

17. Wolf Klein GP, Silverstone FA, Levy AP. Nutritional patterns and weight change in Alzheimer patients. Int Psychogeriatr 1992;4:103-118. https://doi.org/10.1017/ s1041610292000930

18. Berlinger WG, Potter JF. Low body mass index in demented outpatients. J Am Geriatr Soc 1991;39:973978. https://doi.org/10.1111/j.1532-5415.1991. tb04043.x
19. Grundman M, Corey Bloom J, Jernigan T, Archibald $\mathrm{S}$, Thal LJ. Low body weight in Alzheimer's disease is associated with mesial temporal cortex atrophy. Neurology 1996;46:1585-1591. https://doi.org/10.1212/ wnl.46.6.1585

20. Morris MC. The role of nutrition in Alzheimer's disease: epidemiological evidence. Eur J Neurol 2009;16:1-7 https://doi.org/10.1111/j.1468-1331.2009.02735.x

21. Kontush K, Schekatolina S. Vitamin $E$ in neurodegenerative disorders: Alzheimer's disease. Ann N Y Acad Sci 2004;1031:249-262. https://doi. org/10.1196/annals.1331.025

22. Vercruysse $P$, Vieau D, Blum D, Petersén A, Dupuis L. Hypothalamic alterations in neurodegenerative diseases and their relation to abnormal energy metabolism. Front Mol Neurosci 2018;11:2. https://doi. org/10.3389/fnmol.2018.00002

23. Cunningham JJ. A reanalysis of the factors influencing basal metabolic rate in normal adults. Amer J Clin Nutr 1980;33:2372-2374. https://doi.org/10.1093/ ajcn/33.11.2372

24. Psota T, Chen KY. Measuring energy expenditure in clinical populations: rewards and challenges. Eur J Clin Nutr 2013;67:436-442. https://doi.org/10.1038/ ejcn.2013.38

25. Wang Z, Heshka S, Zhang K, Boozer CN, Heymsfield $\mathrm{SB}$. Resting energy expenditure: systematic organization and critique of prediction methods. Obes Res 2001;9:331-336. https://doi.org/10.1038/ oby. 2001.42

26. Da Rocha EEM, Alves VGF, da Fonseca RBV. Indirect calorimetry: methodology, instruments and clinical application. Curr Opin Clin Nutr Metab Care 2006;9:247-256. https://doi.org/10.1097/01. mco.0000222107.15548.f5

27. Henry CJK. Basal metabolic rate studies in humans: measurement and development of new equations. Public Health Nutr 2005;8:1133-1152. https://doi. org/10.1079/phn2005801

28. Segura Badilla O, Kammar Garcia A, Vera Lopez O, et al. Simplified equation for resting energy expenditure in a population of elderly chileans compared to indirect calorimetry. NFS Journal 2018;13:23-29. https://doi. org/10.1016/j.nfs.2018.10.002.

29. Bosy Westphal A, Eichhorn C, Kutzner D, Illner K, Heller M, Müller MJ. The age-related decline in resting energy expenditure in humans is due to the loss of fatfree mass and to alterations in its metabolically active components. J Nutr 2003;133:2356-2362. https://doi. org/10.1093/jn/133.7.2356

30. Doorduijn AS, de van der Schueren MAE, van de Rest $\mathrm{O}$, et al. Energy intake and expenditure in patients with Alzheimer's disease and mild cognitive impairment: The NUDAD project. Alzheimer's Research \& Therapy 2020;12:116:1-8. https://doi.org/10.1186/s13195-02000687-2 
31. Niskanen L, Piirainen M, Koljonen M, Uusitupa M. Resting energy expenditure in relation to energy intake in patients with Alzheimer's disease, multiinfarct dementia and in control women. Age Ageing 1993;22:132-137. https://doi.org/10.1093/ ageing/22.2.132

32. Poehlman ET, Dvorak RV. Energy expenditure, energy intake, and weight loss in Alzheimer disease. Am J Clin Nutr 2000;71:650-655. https://doi.org/10.1093/ ajcn/71.2.650s

33. Cova I, Clerici F, Rossi A, et al. Weight loss predicts progression of mild cognitive impairment to Alzheimer's disease. PLoS One 2016;18;11:e0151710. https://doi. org/10.1371/journal.pone.0151710

34. Burns JM, Johnson DK, Watts A, Swerdlow RH, Brooks WM. Reduced lean mass in early Alzheimer disease and its association with brain atrophy. Arch Neurol 2010;67:428-433. https://doi.org/10.1001/ archneurol.2010.38

35. Santos TBND, Fonseca LC, Tedrus GMAS, Delbue JL. Alzheimer's disease: nutritional status and cognitive aspects associated with disease severity. Nutr Hosp 2018;35:1298-1304. https://doi.org/10.20960/nh.2067

36. Dulloo AG, Jacquet J, Miles Chan JL, Schutz Y. Passive and active roles of fat-free mass in the control of energy intake and body composition regulation. Eur J Clin Nutr 2017;71:353-357. https://doi.org/10.1038/ ejcn.2016.256

Etik kurul onayı: Trakya Üniversitesi Tıp Fakültesi Bilimsel Araştırmalar Etik Kurulu'nun 06.01.2020 tarih, 2019/442 sayı ve 01/31 nolu karar ile onay alınmıştır.

\section{Yazarların makaleye olan katkıları}

H.Ö ve A.Ü. çalışmanın ana fikrini ve hipotezini kurgulamışlardır. H.Ö teoriyi geliştirmiş ve materyel metod bölümünü düzenlemiştir. Sonuçlar kısmındaki verilerin değerlendirmesini H.Ö ve A.Ü. yapmışlardır. Makalenin tartışma bölümü H.Ö ve A.Ü. tarafından yazılmış, gözden geçirilmiş, gerekli düzeltmeleri yapılıış ve onaylanmıştır. Ayrıca tüm yazarlar çalışmanın tamamını tartışmış ve son halini onaylamıştır. 